\title{
Effect of oxygenation and temperature on glucose-xylose fermentation in Kluyveromyces marxianus CBS712 strain
}

\author{
Lorenzo Signori ${ }^{1}$, Simone Passolunghi ${ }^{1,3}$, Laura Ruohonen ${ }^{2}$, Danilo Porro ${ }^{1}$ and Paola Branduardi ${ }^{*}$
}

\begin{abstract}
Background: The yeast Kluyveromyces marxianus features specific traits that render it attractive for industrial applications. These include production of ethanol which, together with thermotolerance and the ability to grow with a high specific growth rate on a wide range of substrates, could make it an alternative to Saccharomyces cerevisiae as an ethanol producer. However, its ability to co-ferment C5 and C6 sugars under oxygen-limited conditions is far from being fully characterized.

Results: In the present study, K. marxianus CBS712 strain was cultivated in defined medium with glucose and xylose as carbon source. Ethanol fermentation and sugar consumption of CBS712 were investigated under different oxygen supplies $\left(1.75 \%, 11.00 \%\right.$ and $20.95 \%$ of $\left.\mathrm{O}_{2}\right)$ and different temperatures $\left(30^{\circ} \mathrm{C}\right.$ and $\left.41^{\circ} \mathrm{C}\right)$. By decreasing oxygen supply, independently from the temperature, both biomass production as well as sugar utilization rate were progressively reduced. In all the tested conditions xylose consumption followed glucose exhaustion. Therefore, xylose metabolism was mainly affected by oxygen depletion. Loss in cell viability cannot explain the decrease in sugar consumption rates, as demonstrated by single cell analyses, while cofactor imbalance is commonly considered as the main cause of impairment of the xylose reductase (KmXR) - xylitol dehydrogenase (KmXDH) pathway. Remarkably, when these enzyme activities were assayed in vitro, a significant decrease was observed together with oxygen depletion, not ascribed to reduced transcription of the corresponding genes.

Conclusions: In the present study both oxygen supply and temperature were shown to be key parameters affecting the fermentation capability of sugars in the K. marxianus CBS712 strain. In particular, a direct correlation was observed between the decreased efficiency to consume xylose with the reduced specific activity of the two main enzymes ( $K m X R$ and $K m X D H)$ involved in its catabolism. These data suggest that, in addition to the impairment of the oxidoreductive pathway being determined by the cofactor imbalance, post-transcriptional and/or post-translational regulation of the pathway enzymes contributes to the efficiency of xylose catabolism in micro-aerobic conditions. Overall, the presented work provides novel information on the fermentation capability of the CBS712 strain that is currently considered as the reference strain of the genus $K$. marxianus.
\end{abstract}

Keywords: Kluyveromyces marxianus, Glucose fermentation, Xylose fermentation, Ethanol production, Oxygen requirement, Xylose reductase, Xylitol dehydrogenase

\footnotetext{
* Correspondence: paola.branduardi@unimib.it

'University of Milano Bicocca, Piazza della Scienza 2, 20126 Milan, Italy

Full list of author information is available at the end of the article
} 


\section{Background}

Modern yeast biotechnology places great emphasis on developing new traits in already established yeast cell factories as well as in identifying yeast species with novel traits or properties [1]. Saccharomyces cerevisiae has been used in biotechnological processes for centuries and it is therefore the best known and established yeast workhorse. However, in the last years, modern genetic and molecular techniques are promoting and facilitating the so-called non-conventional yeasts being reconsidered as alternative cell factories (as discussed in [2,3]). Among the nonSaccharomyces or non-conventional yeasts with potential for industrial applications are those belonging to the genus Kluyveromyces.

Within this genus Kluyveromyces marxianus, Kluyveromyces lactis, Kluyveromyces aestuarii, Kluyveromyces dobzhanskii and Kluyveromyces wickerhamii are highly related and appear clearly separated from the other Kluyveromyces species [4].

$K$. lactis is a model Crabtree-negative yeast that has been extensively investigated [5-7]. Since 1950s it has been used as a natural source of enzymes such as lactase/ $\beta$-galactosidase, [8] and as a protein supplement in food [7]. From 1980s onwards, its easiness to genetic manipulations was recognized, and subsequently, suitable genetic tools have been developed, rendering it an efficient host for recombinant production $[7,9,10]$.

K. marxianus has up to now received less attention from the scientific community [11], in spite of some very interesting characteristics such as the highest specific growth rate among eukaryotic microbes [12], the ability to grow at temperature up to $45-52^{\circ} \mathrm{C}$ [13-16], and the capacity of metabolizing a wide range of substrates including glucose, mannose, galactose, lactose, but also the pentose sugars xylose and arabinose [17]. These features could make K. marxianus an alternative to $S$. cerevisiae as an ethanol producer from lignocellulosic sugars [17-20]. Currently, S. cerevisiae plays the major role in ethanol production due to its high ethanol productivity, tolerance and its efficient hexose fermentation $[21,22]$. However, its inability to ferment xylose and other C5 sugars constitutes a major obstacle to efficient conversion of lignocellulose to ethanol. Moreover, thermotolerant yeast applicable for high temperature fermentation are expected to have potential in reducing cooling costs, increasing saccharification and fermentation rates, facilitating continuous ethanol removal and minimizing contaminations $[13,16,23]$. Also in this respect $S$. cerevisiae displays limitations, due to its very low fermentation efficiency at high temperature $\left(>35^{\circ} \mathrm{C}\right.$, [24]). Therefore, the natural ability of $K$. marxianus to metabolize xylose, which is the main C5 sugar present in lignocellulosic hydrolysates and the second most abundant fermentable material [25], and its remarkable thermotolerance are particularly relevant when lignocellulose is used as raw material.
Strains belonging to the $K$. marxianus species have been isolated from a great variety of habitats, resulting in a genetic polymorphism which has been the focus of several studies [26,27].

This great variety, together with lack of published research on physiology, metabolism and biochemistry are possible reasons as to why a $K$. marxianus industrial strain, which could constitute a real alternative to $S$. cerevisiae for ethanol production has not been developed yet.

The strain CBS712 is currently considered as the reference strain of the genus $K$. marxianus [3] being the most studied also at the genomic level, with about $20 \%$ of its genome randomly sequenced [28]. Despite its ethanol production yield being very low compared to that of other strains of the same species, the fact that its genome is partially available, offers the possibility of future in silico analyses based on additional wet lab data on its metabolic capabilities.

In the present study batch fermentations under different temperatures and oxygen supplies with $K$. marxianus CBS712 were performed: the potential for xylose utilization and ethanol production was investigated, together with quantitative measurements of biomass formation, substrate consumption and external metabolite accumulation. Cell viability and oxidative stress response to the process conditions were additionally monitored by flow cytometric analyses. It has been reported that $K$. marxianus CBS712 can assimilate xylose but its ability to produce ethanol from xylose is coupled to oxygen feed [25]. Interestingly, the in vitro activity measurements of xylose reductase (KmXR) and xylitol dehydrogenase $(\mathrm{KmXDH})$ demonstrated that the more the oxygen supply was restricted, the more the respective activities diminished, but with no corresponding decrease of mRNA levels. Therefore, the cofactor imbalance of the $K m \mathrm{XR} / \mathrm{KmXDH}$ pathway, particularly pronounced under oxygen limitation [29], seems not the only explanation for the limited capacity of xylose fermentation in the K. marxianus CBS712 strain.

\section{Results}

Growth and fermentation profiles of $K$. marxianus CBS712 at $30^{\circ} \mathrm{C}$ with different inlet oxygen concentrations on mixture of glucose and xylose

The $K$. marxianus strain CBS712 was cultivated in batch mode in minimal defined medium [30] with xylose $\left(20 \mathrm{~g} \mathrm{~L}^{-1}\right)$ and glucose $\left(20 \mathrm{~g} \mathrm{~L}^{-1}\right)$ as carbon and energy source to evaluate the eventual sugar co-consumption, highly desirable for lignocellulosic second-generation ethanol production. Fermentations were performed at $30^{\circ} \mathrm{C}, \mathrm{pH} 5$ and followed for 70 hours. The inlet gas flow rate was maintained constant at $0.2 \mathrm{vvm}$ (corresponding to $0.3 \mathrm{~L} \mathrm{~min}^{-1}$ ). The effect of three different concentrations of oxygen in the inlet gas flow, 20.95\%, 11.00\% and $1.75 \%$, were monitored. For all the conditions studied, the dissolved oxygen fraction decreased to zero within 
10 hours of growth. It has been reported that some strains of $K$. marxianus do not grow in anoxic conditions (as reviewed by [26]), while others do [31]. For this reason, at first it was verified that the model strain selected for the present study did not grow under anaerobic batch conditions (data not shown): therefore, fully anaerobic cultures were not assessed.

Figure 1 (left panels) shows the gas profiles of the three processes. The profiles of both $\mathrm{O}_{2}$ and $\mathrm{CO}_{2}$ over time were clearly related to the oxygen concentration of the inlet gas flow. Those of $\mathrm{CO}_{2}$ deserve some attention. Indeed, not only the total amount of $\mathrm{CO}_{2}$ produced, but also the maximum peak of production clearly appeared correlated with the amount of oxygen supplied in the gas flow. With the highest oxygen supply (Figure 1, left panel a), the peak of $\mathrm{CO}_{2}$ production was reached after $9.5 \pm 0.2$ hours from the inoculum, but only after $11.3 \pm 0.2$ hours with the lowest oxygen supply (left panel c). These differences were reflected on the profiles of sugar consumption and product accumulation as deduced by the measured samples, Figure 1, right panels. First of all, the production of biomass (closed triangles) was directly related to the oxygen supply, being proportionally lower for the lower concentrations of the inlet oxygen. Furthermore, and as already reported in literature, the CBS712 strain exhibited a delayed utilization of xylose (open squares), which was never significantly consumed until complete glucose (closed squares) exhaustion. Overall, also the xylose consumption appeared related to the concentration of the inlet oxygen, decreasing with the decrease of the oxygen supply: indeed, the amount of xylose consumed after $70 \mathrm{~h}$ of fermentation was about $12 \mathrm{~g} \mathrm{~L}^{-1}$ and $5.9 \mathrm{~g} \mathrm{~L}^{-1}$ with $20.95 \%$ and $11.00 \%$ of oxygen, respectively, and only about $1.5 \mathrm{~g} \mathrm{~L}^{-1}$ with $1.75 \%$ of oxygen (right panels $\mathrm{a}, \mathrm{b}, \mathrm{c}$ ). The peaks of $\mathrm{CO}_{2}$

\section{$30^{\circ} \mathrm{C}$}
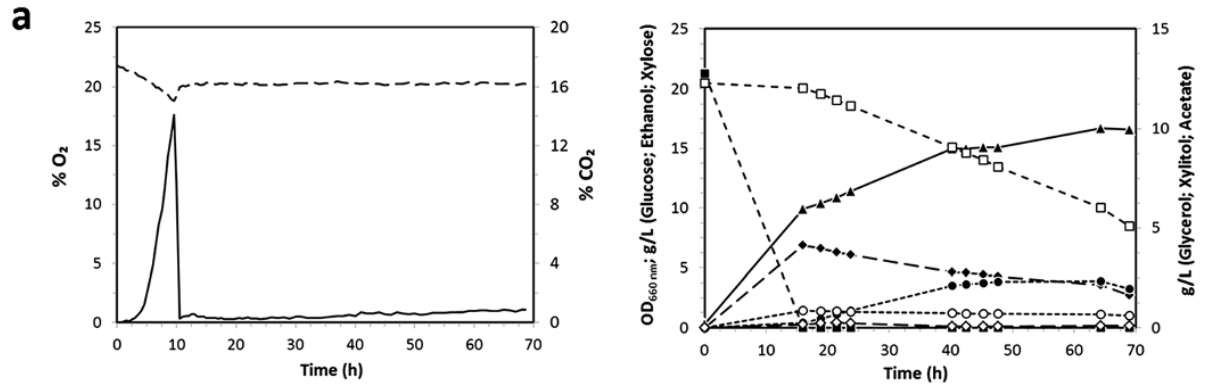

b
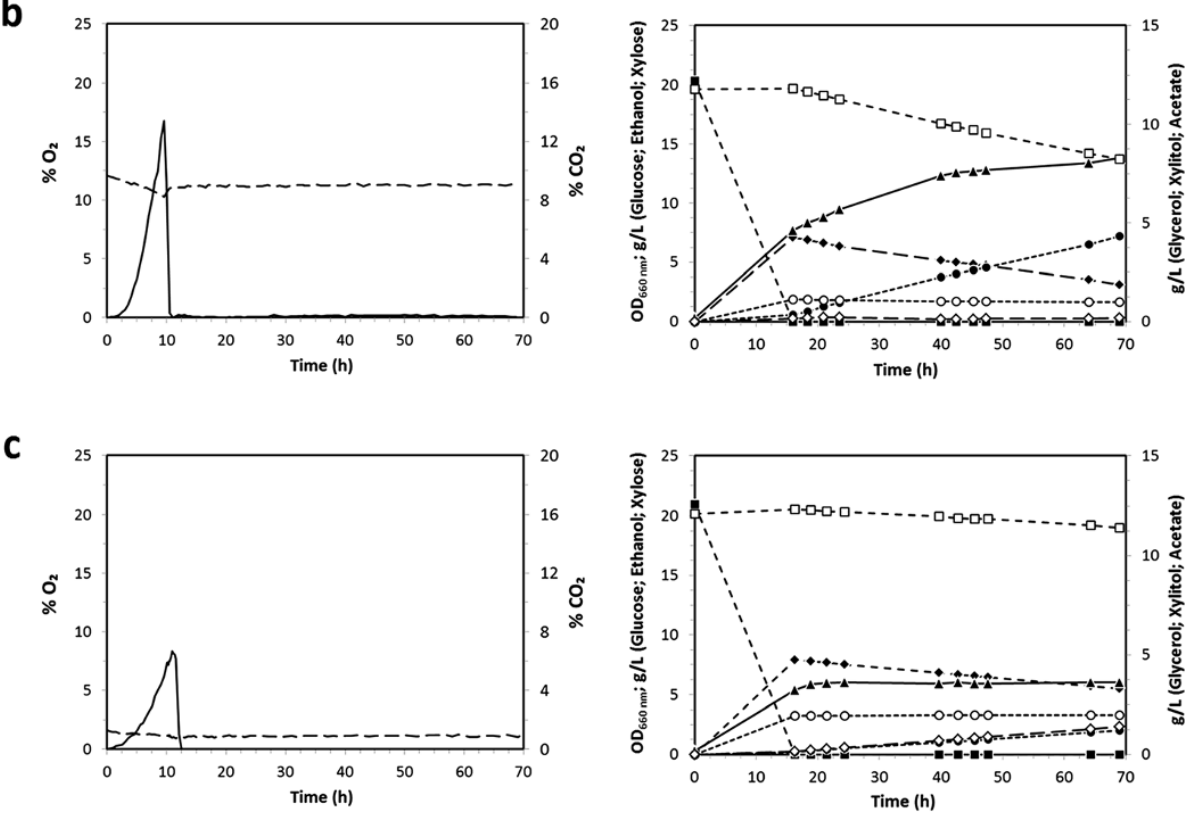

Figure 1 Fermentation profiles of $K$. marxianus $\mathrm{CBS7} 12$ at $30^{\circ} \mathrm{C}$. Fermentation profiles of $K$. marxianus $\mathrm{CBS} 712$ grown at $30^{\circ} \mathrm{C}$ under different concentrations of inlet oxygen: 20.95\% (a), 11.00\% (b), and 1.75\% (c). Left panels: $\mathrm{O}_{2}$ (\%; dashed line) and $\mathrm{CO}_{2}$ (\%; continuous line) profiles. Right panels: Biomass $\left(\mathrm{OD}_{660} ; \mathbf{\Delta}\right)$, Glucose $\left(\mathrm{g} \mathrm{L}^{-1} ; \mathbf{-}\right)$, Ethanol $\left(\mathrm{g} \mathrm{L}^{-1} ; \bullet\right)$, Xylose $\left(\mathrm{g} \mathrm{L}^{-1} ; \square\right)$, Acetate $\left(\mathrm{g} \mathrm{L}^{-1} ; \bullet\right)$, Glycerol $\left(\mathrm{g} \mathrm{L}^{-1} ; \circ\right)$ and Xylitol $\left(\mathrm{g} \mathrm{L}^{-1} ; \diamond\right)$. Results are average values of three replicates where the deviation from the mean value was always less than $5 \%$. 
production (left panels) seemed to correlate with the onset of xylose consumption (or more precisely, with the glucose consumption being completed, see also below). Therefore, both biomass accumulation and the rate of sugar utilization were progressively decreased as the stringency of the oxygen supply increased (Table 1).

Ethanol production (closed diamonds) was in essence only observed during the exponential growth on glucose. Interestingly, similar amounts of ethanol were measured under the three different conditions. We can safely speculate that the highest level of ethanol accumulation correlated with the peak of $\mathrm{CO}_{2}$ production (compare left with right panels).

As shown in Figure 1 (right panels), no noticeable ethanol production was detected during the xylose consumption phase of the batch fermentations. However, the CBS712 strain was able to produce ethanol from xylose, even if with very low yields, between 0.08 and $0.09 \mathrm{~g} \mathrm{~g}^{-1}$. These experiments were performed in shake flasks with xylose $\left(20 \mathrm{~g} \mathrm{~L}^{-1}\right)$ as the sole carbon source, both at $30^{\circ} \mathrm{C}$ and $41^{\circ} \mathrm{C}$, with similar results (data not shown).

With the exhaustion of glucose and the onset of xylose consumption a decrease in the ethanol concentration was observed, being the trend of xylose and ethanol profiles very likely an indication of their co-consumption. In fact, evaporation tests (data not shown), performed under the same operative conditions demonstrated that stripping was not sufficient to explain the decrease in the ethanol concentration. This suggests that the CBS712 strain grows on ethanol after glucose exhaustion: in detail, it consumed $\sim 1 \mathrm{~g} \mathrm{~L}^{-1}$ and $\sim 3 \mathrm{~g} \mathrm{~L}^{-1}$ of ethanol with the lowest $\left(1.75 \% \mathrm{O}_{2}\right)$ and the highest (20.95\%) oxygen supply, respectively.

The lower the oxygen supply, the higher was the glycerol (open circles) and xylitol (open diamonds) accumulation. Production of glycerol can be described as an alternative way to ethanol of recycling $\mathrm{NADH}$ to $\mathrm{NAD}^{+}$[32]. However, as already reported in literature for oxygen-limited conditions $[29,33]$, the inefficient regeneration of $\mathrm{NAD}^{+}$led also to xylitol accumulation. Acetate (closed circles) was produced in consistent amounts with high and medium oxygen supplies (Figure 1, right panels a and b), while its accumulation was limited under $1.75 \%$ oxygen inlet (panel c).

\section{Growth and fermentation profiles of $K$. marxianus CBS712 at $41^{\circ} \mathrm{C}$ with different inlet oxygen concentrations on mixture of glucose and xylose}

To evaluate the influence of temperature, the experiments described were repeated at $41^{\circ} \mathrm{C}$, Figure 2. From a general point of view, the gas profiles showed similar trends (compare Figure 1 and Figure 2, left panels). However, at $41^{\circ} \mathrm{C}$ the $\mathrm{CO}_{2}$ production rates (and therefore the glucose consumption rates) were markedly faster than at $30^{\circ} \mathrm{C}$. Consequently, the onset and efficiency of xylose consumption was also more rapid at oxygen supply of $20.95 \%$ and $11.00 \%$ than at the lower temperature assessed. Once more, the kinetic profile suggests an apparent glucosexylose co-consumption, very likely only a consequence of the sampling time, as also verified in shake flasks experiments (data not shown). Remarkably, at $41^{\circ} \mathrm{C}$ the biomass production (closed triangles) with high or medium oxygen supply was significantly lower after glucose exhaustion during the phase of xylose consumption.

As shown in Table 1, and as previously suggested by the $\mathrm{CO}_{2}$ profiles (Figures 1 and 2, left panels), both the amount of oxygen supplied $\left(1.75 \%, 11.00 \%\right.$ and $20.95 \%$ of $\mathrm{O}_{2}$ ) and temperature $\left(30\right.$ and $\left.41^{\circ} \mathrm{C}\right)$ affected the overall glucose consumption rate. In particular, at $41^{\circ} \mathrm{C}$ and independently from the oxygen supply, the glucose consumption rates were faster than at $30^{\circ} \mathrm{C}$ : at $41^{\circ} \mathrm{C}$ the lowest glucose consumption rate was $\sim 2.80 \mathrm{~g} \mathrm{~L}^{-1} \mathrm{~h}^{-1}\left(1.75 \%\right.$ of $\left.\mathrm{O}_{2}\right)$ while at

Table 1 Sugars consumption rates and ethanol production rates

\begin{tabular}{|c|c|c|c|c|c|c|c|c|c|c|c|c|}
\hline \multirow[t]{2}{*}{$\mathrm{T}^{\mathrm{a}}\left({ }^{\circ} \mathrm{C}\right)$} & \multirow[t]{2}{*}{$\mathrm{O}_{2}^{\mathrm{b}}(\%)$} & \multicolumn{7}{|c|}{ Volumetric consumption and production rates $\left(\mathrm{gL}^{-1} \mathrm{~h}^{-1}\right)$} & \multicolumn{4}{|c|}{ Yields $\left(\mathrm{gg}^{-1}\right)$} \\
\hline & & Glucose & Xylose & Ethanol & Biomass & Glycerol & Acetate & Xylitol & Biomass & Glycerol & Acetate & Xylitol \\
\hline \multirow[t]{3}{*}{$30^{\circ} \mathrm{C}$} & 20.95 & 2,23 & 0,21 & 0,77 & 0,08 & n.d. ${ }^{c}$ & 0,04 & n.d. ${ }^{c}$ & 0,17 & 0,02 & 0,07 & n.d. $^{c}$ \\
\hline & 11.00 & 2,13 & 0,11 & 0,79 & 0,07 & 0,01 & 0,07 & n.d. ${ }^{c}$ & 0,17 & 0,03 & 0,16 & n.d. ${ }^{c}$ \\
\hline & 1.75 & 1,94 & 0,03 & 0,76 & 0,03 & 0,02 & 0,02 & 0,02 & 0,09 & 0,08 & 0,05 & 0,79 \\
\hline \multirow[t]{3}{*}{$41^{\circ} \mathrm{C}$} & 20.95 & 3,22 & 0,14 & 0,15 & 0,05 & 0,01 & 0,13 & n.d. ${ }^{c}$ & 0,10 & 0,03 & 0,26 & n.d. ${ }^{c}$ \\
\hline & 11.00 & 3,16 & 0,15 & 1,18 & 0,05 & 0,01 & 0,11 & n.d. ${ }^{c}$ & 0,11 & 0,04 & 0,24 & n.d. ${ }^{c}$ \\
\hline & 1.75 & 2,80 & 0,05 & 1,12 & 0,03 & 0,02 & 0,03 & 0,04 & 0,08 & 0,09 & 0,08 & 0,75 \\
\hline
\end{tabular}

${ }^{\mathrm{a}} \mathrm{T}$, temperature.

${ }^{\mathrm{b}} \mathrm{O}_{2}$, inlet oxygen.

cn.d., not detectable.

Sugar (glucose and xylose) consumption rates, production rates (biomass, ethanol, glycerol, acetate and xylitol) and yields (biomass, glycerol, acetate and xylitol) at different temperature and oxygen supply. Glucose consumption rates were calculated during the $\mathrm{CO}_{2}$ production phase, while xylose consumption rates were calculated starting from the first point after glucose exhaustion until the last point of the fermentation. Ethanol production rates relate only to the glucose consumption phase since on xylose consumption phase, in all the tested conditions, no significant ethanol production was observed. Yields and volumetric production rates of biomass, glycerol and acetate were calculated based on the total consumed sugars, while xylitol yields and volumetric production rates were calculated based on the consumed xylose only.

The results shown are average values of three replicates where the deviation from the mean value was always less than $3 \%$. 


\section{$41^{\circ} \mathrm{C}$}
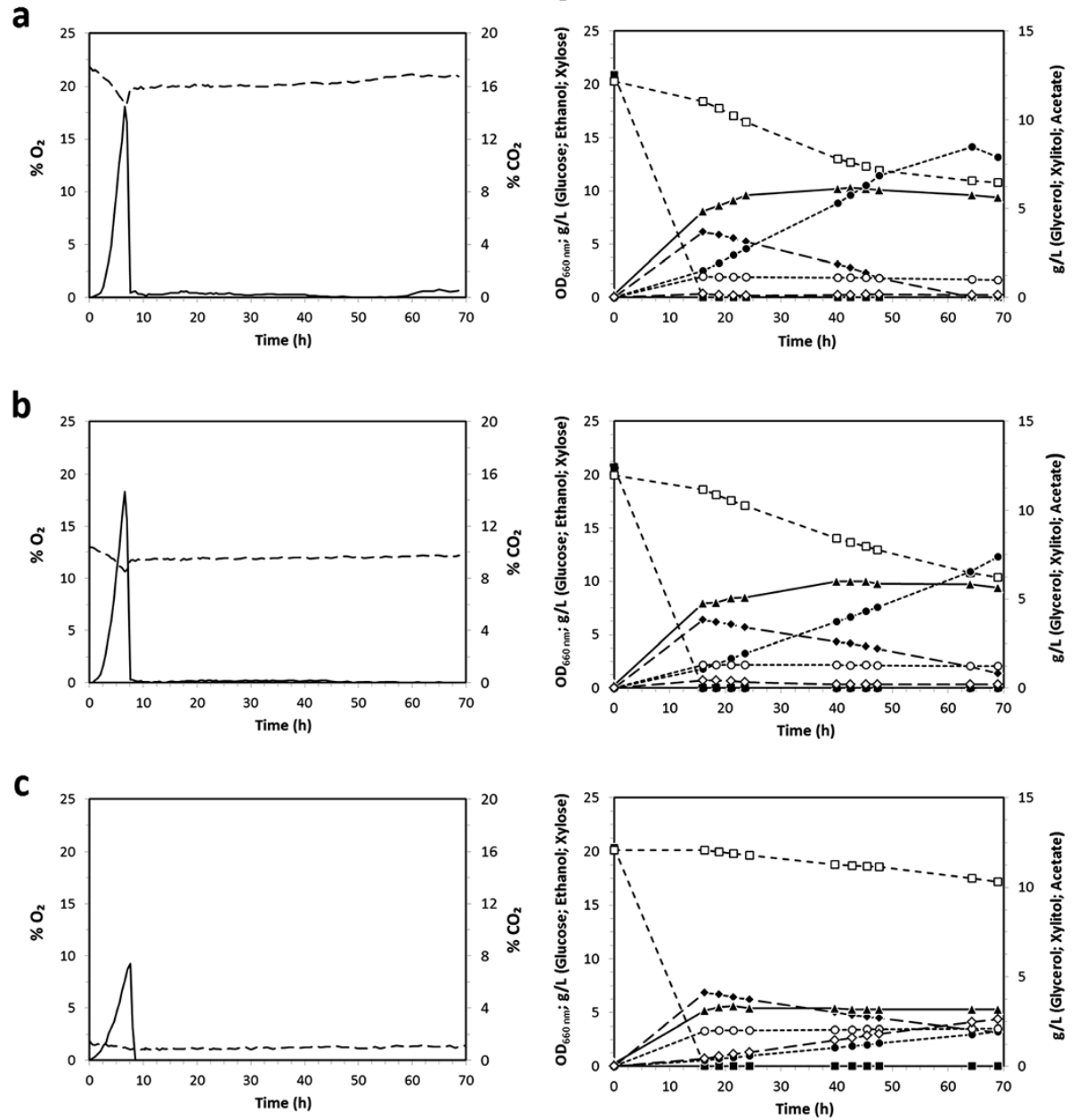

Figure 2 Fermentation profiles of $K$. marxianus CBS712 at $41^{\circ} \mathrm{C}$. Fermentation profiles of $K$. marxianus $\mathrm{CBS} 712$ grown at $41^{\circ} \mathrm{C}$ under different concentrations of inlet oxygen: 20.95\% (a), $11.00 \%$ (b), and 1.75\% (c). Left panels: $\mathrm{O}_{2}$ (\%; dashed line) and $\mathrm{CO}_{2}$ (\%; continuous line) profiles. Right panels: Biomass $\left(\mathrm{OD}_{660} ; \boldsymbol{\Delta}\right)$, Glucose $\left(\mathrm{g} \mathrm{L}^{-1} ; \boldsymbol{\bullet}\right)$, Ethanol $\left(\mathrm{g} \mathrm{L}^{-1} ; \bullet\right)$, Xylose $\left(\mathrm{g} \mathrm{L}^{-1} ; \square\right)$, Acetate $\left(\mathrm{g} \mathrm{L}^{-1} ; \bullet\right)$, Glycerol $\left(\mathrm{g} \mathrm{L}^{-1} ; \circ\right)$ and Xylitol $\left(\mathrm{g} \mathrm{L}^{-1} ; \diamond\right)$. Results are average values of three replicates where the deviation from the mean value was always less than $5 \%$.

$30^{\circ} \mathrm{C}$ the highest consumption rate was $\sim 2.23 \mathrm{~g} \mathrm{~L}^{-1} \mathrm{~h}^{-1}$ $\left(20.95 \%\right.$ of $\left.\mathrm{O}_{2}\right)$. Overall, the glucose consumption rates were more influenced by changes in temperature than by changes in the oxygen supply.

Also at the higher temperature ethanol was produced only during the exponential growth on glucose and at similar levels. However, at $41^{\circ} \mathrm{C}$ the ethanol production rates were markedly faster than at $30^{\circ} \mathrm{C}$, as expected by the observed glucose consumption rates (Table 1).

Interestingly, the amount of oxygen supplied did not significantly affect the ethanol production rates, even if at both temperatures $\left(30\right.$ and $41^{\circ} \mathrm{C}$ ) the same trend was observed: the lower ethanol production rates were observed with $1.75 \%$ of inlet oxygen $\left(\sim 0.76 \mathrm{~g} \mathrm{~L}^{-1} \mathrm{~h}^{-1}\right.$ and $\sim 1.12 \mathrm{~g} \mathrm{~L}^{-1} \mathrm{~h}^{-1}$ at 30 and $41^{\circ} \mathrm{C}$, respectively) while the highest production rates were observed with $11.00 \%$ of inlet oxygen $(\sim 0.79 \mathrm{~g}$ $\mathrm{L}^{-1} \mathrm{~h}^{-1}$ and $\sim 1.18 \mathrm{~g} \mathrm{~L}^{-1} \mathrm{~h}^{-1}$ at 30 and $41^{\circ} \mathrm{C}$, respectively).
Also at $41^{\circ} \mathrm{C}$, evaporation tests (data not shown) demonstrated that stripping, even if higher than that observed at $30^{\circ} \mathrm{C}$, was not sufficient to explain the decrease in ethanol concentration(s), suggesting a co-consumption of ethanol and xylose.

Table 1 also reports the xylose consumption phase after glucose exhaustion: while at $30^{\circ} \mathrm{C}$ the xylose consumption rate was by far the highest with $20.95 \%$ of inlet oxygen $\left(\sim 0.21 \mathrm{~g} \mathrm{~L}^{-1} \mathrm{~h}^{-1}\right)$, at $41^{\circ} \mathrm{C}$ significant differences were not observed between high or medium oxygen supply ( 0.14 $\mathrm{g} \mathrm{L}^{-1} \mathrm{~h}^{-1}$ and $\sim 0.15 \mathrm{~g} \mathrm{~L}^{-1} \mathrm{~h}^{-1}$, respectively).

These values underline once more that both the oxygen feeding and temperature are key parameters for the ability of CBS712 strain to consume xylose.

Like previously observed at $30^{\circ} \mathrm{C}$, xylitol (open diamonds) and glycerol (open circles) accumulation increased at the lowest inlet of oxygen supply. Overall, the 
highest concentration of xylitol was assessed at $41^{\circ} \mathrm{C}$ with $1.75 \%$ of inlet oxygen, with consumption of $3 \mathrm{~g} \mathrm{~L}^{-1}$ of xylose and accumulation of $2.7 \mathrm{~g} \mathrm{~L}^{-1}$ of xylitol, corresponding to a yield of $0.75 \mathrm{gg}^{-1}$. In the same condition the highest glycerol accumulation and yield $\left(2.1 \mathrm{~g} \mathrm{~L}^{-1}\right.$ and $0.09 \mathrm{gg}^{-1}$, respectively) was also measured (Table 1 ).

Finally, at $41^{\circ} \mathrm{C}$ greater accumulation of acetate compared to the fermentations at $30^{\circ} \mathrm{C}$ was observed (Figures 2 and 1, closed circles, respectively). As an example, with $20.95 \%$ of oxygen, the highest acetic acid production and yield were $8.5 \mathrm{~g} \mathrm{~L}^{-1}$ and $0.26 \mathrm{gg}^{-1}$ compared to $2.3 \mathrm{~g} \mathrm{~L}^{-1}$ and $0.06 \mathrm{gg}^{-1}$ at $41^{\circ} \mathrm{C}$ and $30^{\circ} \mathrm{C}$, respectively (Table 1 ).

\section{Viability and intracellular ROS accumulation assessed by flow cytometric analyses}

Cellular viability, or more generally active metabolism and cellular integrity, can strongly influence substrate uptake and production rates of biomass and metabolites. Therefore, a set of analyses at single cell level was performed to evaluate this parameter during the fermentation processes previously described. Cells were collected at different time points $(\mathrm{T}=16, \mathrm{~T}=40$ and $\mathrm{T}=64$ hours after inoculation, see Figures 1, 2), stained with propidium iodide (PI) and analysed by flow-cytometry to detect severely damaged/dead cells ([34], see Materials and methods). In Figure 3 the percentages of severely damaged/dead cells in the different conditions tested are reported.

Generally speaking, the percentages of PI positive cells were very low, independent from the fermentation parameters. In particular, at $30^{\circ} \mathrm{C}$ such fraction never exceeded $5 \%$ of the whole population. At $41^{\circ} \mathrm{C}$ the percentages were a bit higher, slightly rising along the time and with the decreasing oxygen supply. Overall, the percentages of damaged cells appeared negligible in respect to the whole population, suggesting that the imposed process conditions did not severely affect the cell viability/integrity. Consequently, low viability does not seem to be the reason for the low xylose consumption rates.

Cells were also stained with dihydrorhodamine-123 (DHR-123) to detect intracellular accumulation of reactive oxygen species (ROS; [35], see Materials and methods, Figure 4). Surprisingly, at $30^{\circ} \mathrm{C}$ a high percentage of cells accumulated ROS under all the process conditions tested, Figure 4 left panels (being lower but still significant only during the first time point measured with the highest oxygen inlet). In contrast, at $41^{\circ} \mathrm{C}$ a progressive decrease in the comparably high intracellular ROS accumulation was observed, right panels. These trends were also confirmed by fluorescence microscopy analyses (data not shown). Data currently available are not sufficient to unambiguously explain either the high ROS accumulation both at $30^{\circ} \mathrm{C}$ and $41^{\circ} \mathrm{C}$, or the decrease over time in ROS accumulation observed at $41^{\circ} \mathrm{C}$. However, these results are further evidence of the different cellular metabolism at $30^{\circ} \mathrm{C}$ and $41^{\circ} \mathrm{C}$, as previously commented (Figure $1 \mathrm{vs}$. Figure 2).

\section{Activity and transcript level of xylose reductase ( $K m \mathrm{XR})$ and the xylitol dehydrogenase $(\mathrm{KmXDH})$}

Xylose reductase $(K m \mathrm{XR})$ and xylitol dehydrogenase $(\mathrm{KmXDH})$ are the two key enzymes of xylose metabolism in $K$. marxianus [25,29,36], like in most other xyloseconsuming yeast.

Aiming at further understanding of the xylose consumption pathway in the $K$. marxianus CBS712 strain, the activity of these two enzymes was determined during the xylose consumption phase of the batch cultures studied, Table 2. To simplify the interpretation of the data, only the two extreme conditions (20.95\% and $1.75 \%$ inlet oxygen) are reported, being the data obtained with $20.95 \%$ and $11.00 \%$ inlet oxygen very similar. At both temperatures and all time points, the specific $K m \mathrm{XDH}$ activities were always higher than the specific $K m \mathrm{XR}$ activities. Overall, it can be noticed that for both activities, independently from the temperature, the higher values related to the higher inlet oxygen (Table 2). In detail, $K m$ XR activity dropped almost to half when the inlet oxygen decreased from $20.95 \%$ to $1.75 \%$ at $30^{\circ} \mathrm{C}$, while the reduction was less evident, if even present, at $41^{\circ} \mathrm{C}$ (where actually an increasing trend in the activity was observed). The inlet oxygen decrease (from $20.95 \%$ to $1.75 \%$ ) determined a decrease also for the $K m \mathrm{XDH}$ activity. However, differently to what previously observed for the $K m \mathrm{XR}$ activity, the reduction was very dramatic at $41^{\circ} \mathrm{C}$, approaching one order of magnitude. At $30^{\circ} \mathrm{C}$, the initial decrease to less than one third (see data at early time point) was followed by an increase along the time, despite values never reaching the ones measured from samples collected from cultures at $20.95 \%$ of inlet oxygen.

It has to be highlighted that the enzymatic activities were assayed in vitro: this means that cofactor imbalance due to the different cofactor preferences of the two enzymes, which is commonly recognized as the limiting factor of this metabolic pathway under limited oxygen conditions [37], cannot be the explanation for the reduced activities measured, and the correlation with the fermentation profiles is not trivial. In fact, by looking once more at the data of the cultures at $30^{\circ} \mathrm{C}$, both of the activities, in particular that of $\mathrm{KmXDH}$, were lower at the two earlier time points assayed, but had increased at the last measurement point (40 h), while the xylose metabolism remained unchanged (see again Figure 1, open squares). On the other hand, from these data it can be concluded that $K m \mathrm{XDH}$ was the most affected enzyme by the oxygen supply, justifying in this case the previously described trends of xylitol accumulation (Figures 1 and 2 open diamonds): the 


\section{$30^{\circ} \mathrm{C}$}

a

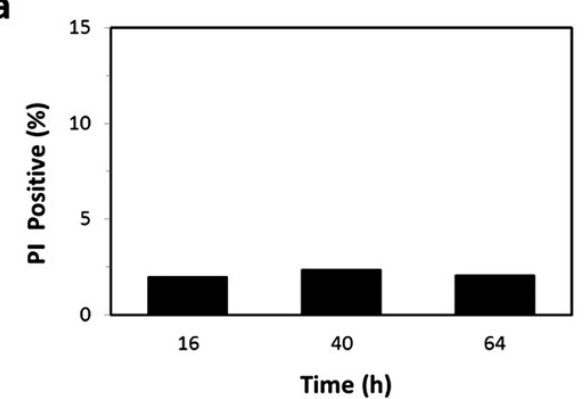

b

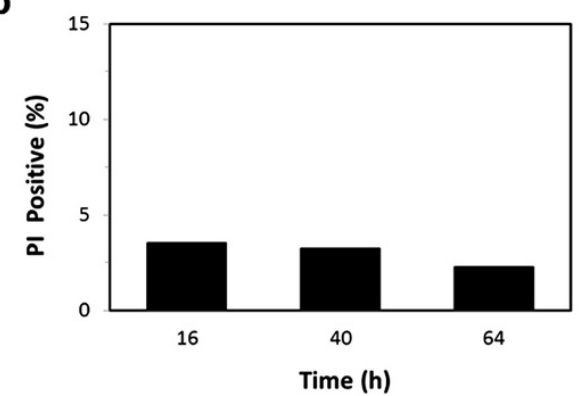

C

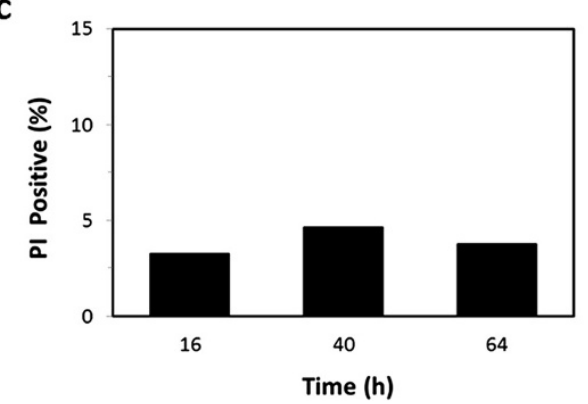

$41^{\circ} \mathrm{C}$
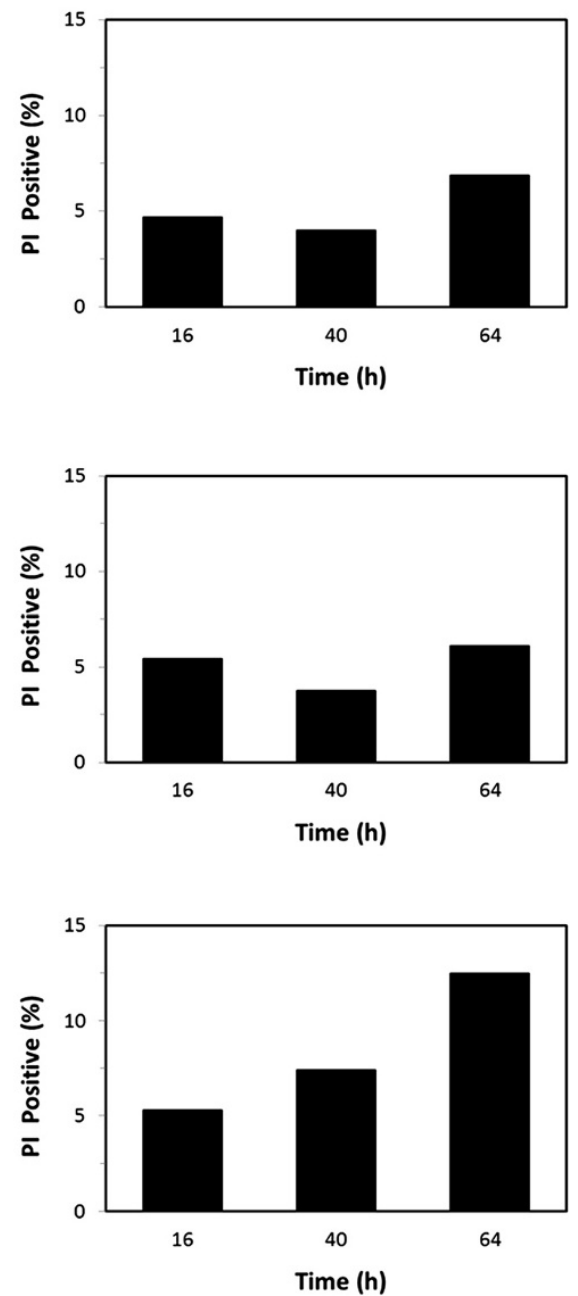

Figure 3 Cell viability. Percentage of damaged/dead cells during fermentations at $30^{\circ} \mathrm{C}$ (left panels) and $41^{\circ} \mathrm{C}$ (right panels) under different concentrations of inlet oxygen: $20.95 \%$ (a), $11.00 \%$ (b) and $1.75 \%$ (c). The results shown are average values of three replicates where the deviation from the mean value was always less than $5 \%$.

higher accumulation of xylitol corresponded to the lower $K m X D H$ specific activity.

Differences in transcription profiles could explain the trend of the enzymatic activities observed. Thus, transcript levels were determined at different time points ( $\mathrm{T}=16, \mathrm{~T}=40$ and $\mathrm{T}=64 \mathrm{~h}$ ) during the fermentations described in Figures 1 and 2. However, the $K m X R$ and $K m \mathrm{XDH}$ expression profiles showed no significant variation at any of the time points studied at the two different temperatures (data not shown). This suggests that, not excluding the impairment determined by cofactor imbalance, post-transcriptional and/or post-translational regulation of the $K m \mathrm{XR}-\mathrm{XDH}$ xylose pathway plays a role in determining the efficiency of xylose metabolism in micro-aerobic conditions in the CBS712 strain of K. marxianus.

\section{Discussion}

The aim of the present study was to characterize the fermentation profiles of the $K$. marxianus CBS712 strain during growth in defined medium with glucose and xylose as carbon source, and with different oxygen supply mimicking the micro-aerobiosis conditions occurring in industrial processes. Moreover, to exploit the peculiar thermotolerance of this yeast, different operative temperatures were compared (see Materials and methods). These conditions, despite still far from a real process of second generation ethanol production, provide useful wet data for future investigations and in silico analyses. $K$. marxianus CBS712 strain was chosen even if its ethanol production yield is low compared to that of other strains of the same species because it represents the reference strain of the species and, to the best of our 
$30^{\circ} \mathrm{C}$

a

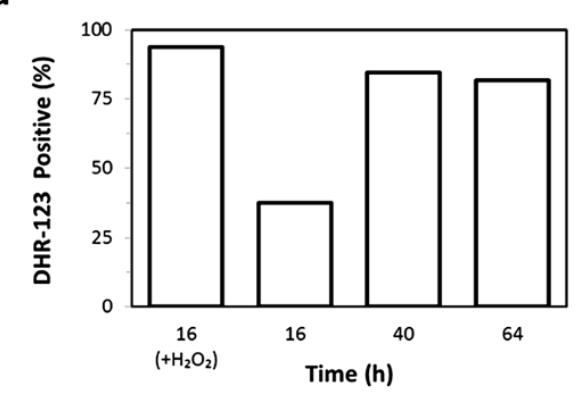

b

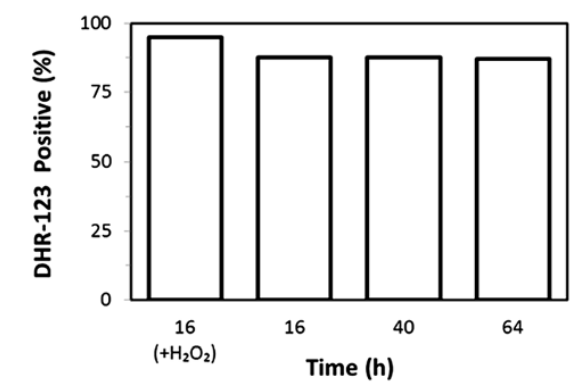

C

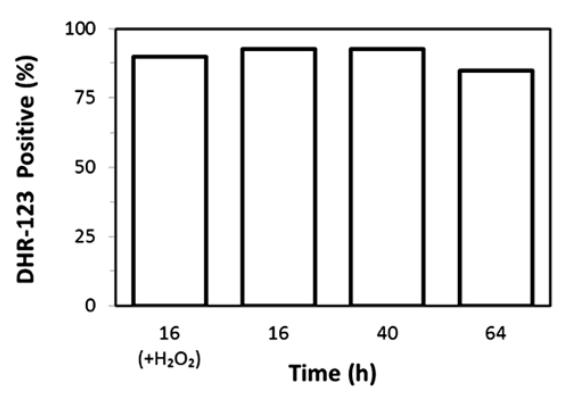

$41^{\circ} \mathrm{C}$
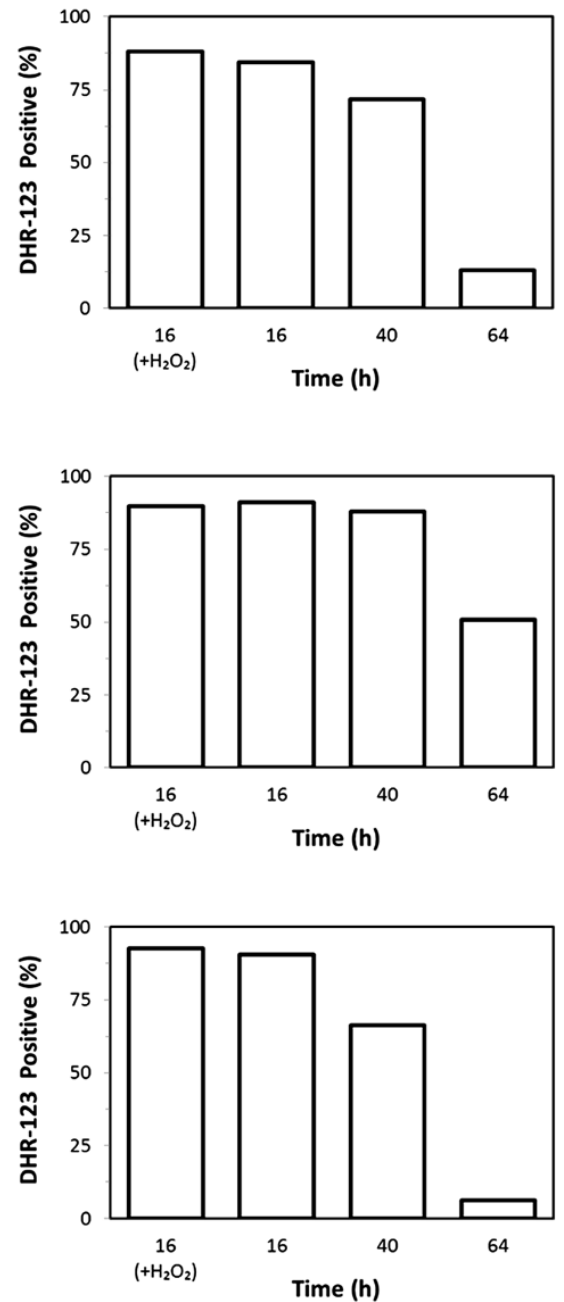

Figure 4 Intracellular ROS accumulation. Percentage of cells that accumulate ROS during fermentations at $30^{\circ} \mathrm{C}$ (left panels) and $41^{\circ} \mathrm{C}$ (right panels) under different concentrations of inlet oxygen: 20.95\% (a), 11.00\% (b), and 1.75\% (c). For each condition, an example of positive control (i.e.: cells treated with $6 \mathrm{mM}$ hydrogen peroxide) is reported. The results shown are average values of three replicates where the deviation from the mean value was always less than $5 \%$.

information, is the only $K$. marxianus strain whose genome has been partially sequenced [28,38].

The data collected allowed describing the metabolic differences occurring by changing either the temperature or the inlet oxygen of the fermentation process. A number of these differences are more directly related to the ethanol production here reported or can be commented in the view of a lignocellulose-based process for ethanol production. They can be summarized as follows: $i$ ) independently from the temperature, the more the oxygen supplied was reduced, the more the metabolism was attenuated, and in particular that of xylose; ii) independently from the oxygen supply, $K$. marxianus CBS712 was able to grow both at 30 and $41^{\circ} \mathrm{C}$, with a faster overall metabolism at $41^{\circ} \mathrm{C}$, as confirmed by the $\mathrm{CO}_{2}$ production rates, which were faster compared to those of fermentations performed at $30^{\circ} \mathrm{C}$. As a possible consequence of an energy demanding condition, the biomass accumulation at $41^{\circ} \mathrm{C}$ was always lower than the corresponding biomass values reached at $30^{\circ} \mathrm{C}$; iii) especially at the higher temperature, there was a significant increase in acetic acid accumulation that might be related to NADPH demand. In fact, it is well reported in literature that not only the pentose phosphate pathway, but also the acetaldehyde dehydrogenase can significantly contribute to the overall NADPH pool $[39,40]$. Additional data would be necessary to fully elucidate this point: however it should be noted that NADPH is the $K m X R$ cofactor [41]. Moreover, since reducing power is required for the neutralization of reactive oxygen species 
Table 2 Xylose reductase (KmXR) and xylitol dehydrogenase (KmXDH) activities

\begin{tabular}{|c|c|c|c|c|c|}
\hline \multirow[t]{2}{*}{ Inlet oxygen (\%) } & \multirow[t]{2}{*}{ Time (h) } & \multicolumn{2}{|c|}{ Enzyme activity $\left(\mathrm{U} \mathrm{mg}^{-1}\right)$} & \multicolumn{2}{|c|}{ Enzyme activity $\left(\mathrm{U} \mathrm{mg}^{-1}\right)$} \\
\hline & & $\mathrm{XR}$ & $\mathrm{XDH}$ & $\mathrm{XR}$ & $\mathrm{XDH}$ \\
\hline \multirow[t]{3}{*}{20.95} & 16 & 6,4 & 45,2 & 6,6 & 39,0 \\
\hline & 23 & 7,4 & 43,9 & 6,1 & 37,9 \\
\hline & 40 & 8,5 & 47,6 & 5,0 & 37,1 \\
\hline \multirow[t]{3}{*}{1.75} & 16 & 3,6 & 13,7 & 3,5 & 4,2 \\
\hline & 23 & 2,3 & 22,3 & 4,6 & 6,3 \\
\hline & 40 & 4,3 & 37,0 & 5,9 & 7,6 \\
\hline
\end{tabular}

Xylose reductase $(\mathrm{KmXR})$ and xylitol dehydrogenase $(\mathrm{KmXDH})$ activities of $K$. marxianus $\mathrm{CBS712}$ grown at $30^{\circ} \mathrm{C}$ and $41^{\circ} \mathrm{C}$ under different inlet oxygen concentrations: $20.95 \%$ (a) and $1.75 \%$ (b) are average values of two replicates where the deviation from the mean value was always less than $3 \%$.

[42,43], NADPH formation through the acetate pathway might be required for counteracting ROS accumulation. This correlates with the overall ROS decrease observed at $41^{\circ} \mathrm{C}$ over time (Figure 4); iv) it is evident that, independently both from the oxygen supply and from the temperature values, the xylose fermentation always followed the glucose consumption (being slower with the lower inlet oxygen, see above). Considering that in the tested conditions the ethanol accumulation was evident only during the glucose phase, it can be concluded that no detectable ethanol production derived from xylose; $v$ ) in the tested conditions, cell viability did not seem to be an issue in $K$. marxianus CBS712, as demonstrated by single cell analysis. This point was addressed since previous reports on fermentation at high temperature evidenced a rapid decrease of cell viability [13]. However, it is important to remember that a very high percentage of cells showed positive in ROS detection; vi) remarkably, the overall ethanol production was very similar in all the tested conditions.

Considering the favourable physiological traits of K. marxianus, glucose-xylose co-fermentation appears as the most urgent to be addressed for lignocellulose-based production. In this respect, the biochemical data well supported how, also in K. marxianus, impairment in xylose metabolism under micro-aerobic condition can be ascribed to the difference in cofactor preference between $K m X R$ and $K m X D H ~[25,29,41]$. Zhang and co-authors [44] overexpressed in K. marxianus a NADPH-preferring xylose reductase and engineered its cofactor preference to revert it to NADH. Data undoubtedly demonstrate the beneficial effect of a higher KmXR specific activity on xylose fermentation, while the advantage of cofactor exchange remains dubious. Not in contrast with that, here we demonstrated that additional regulation may occur at post-transcriptional level, since in vitro measured activities of both $K m \mathrm{XR}$ and $\mathrm{KmXDH}$ were reduced together with inlet oxygen reduction, despite the fact that the preferred cofactors were supplied within the reaction mix. Additionally, no coherent differences in transcription levels of the genes encoding these two enzymes were measured. An alternative way of solving the problem was more recently proposed by Wang and co-authors [45], by substituting the native xylose pathway with the fungal one based on xylose isomerase, providing promising results. It would be very interesting to see if even in this engineered strain glucose represses xylose fermentation, as demonstrated in the native strain for different ratios of these two sugars [46]. Finally, it is interesting to underline once more the high or very high percentage of cells positive in ROS staining: this might prelude to the higher mortality registered when $K$. marxianus cells were grown in the presence of different pre-treated lignocellulose preparations [47,48], which are known to contain pro-oxidative inhibitors, such as acetic acid. In this respect, as already demonstrated for S. cerevisiae [49,50], improving strain robustness can certainly be seen as an additional manipulation target to be conducted for developing $K$. marxianus as a real possible alternative yeast for second generation processes of bio-production.

\section{Conclusions}

The results presented provide data indicating that sugars fermentation in the $K$. marxianus CBS712 strain is affected both by oxygen supply and temperature. Xylose fermentation, and more importantly glucose and xylose cofermentation, under limited oxygen supply is of particular relevance for second generation bioethanol production. Therefore, fermentation profiles and biochemical data on the key metabolic pathway are desirable information for the development of an efficient cell factory. We showed a direct correlation between the decreased efficiency to consume xylose with the reduced specific activity of the two main enzymes (KmXR and $K m \mathrm{XDH})$ involved in its catabolism. Therefore, it is possible to hypothesize that in the CBS712 strain the efficiency of xylose catabolism in micro-aerobic conditions is influenced not only by the cofactor imbalance, but also by post-transcriptional and/or post-translational regulation of the key enzymes of the pathway. Overall, the presented work provides novel information on the fermentation capability of the CBS712 strain that is currently considered as the reference strain of the genus $K$. marxianus. 


\section{Materials and methods}

\section{Yeast strain and inoculum preparation}

The $K$. marxianus strain used in this study was CBS712 (http://www.cbs.knaw.nl, alias NBRC 10005). Strain maintenance: the strain was overnight shake flask cultured in YPX medium $\left(1 \% \mathrm{wv}^{-1}\right.$ yeast extract, $2 \% \mathrm{wv}^{-1}$ peptone, $2 \% \mathrm{wv}^{-1}$ xylose). Sterile glycerol was added to a final concentration of $20 \%\left(\mathrm{vv}^{-1}\right)$ and cells were stored in cryotubes at $-80^{\circ} \mathrm{C}$. Pre-cultures were always prepared transferring some cells from these stock tubes to YPX agar plates and inoculating single colonies (visible after $24 \mathrm{~h}$ of incubation at $30^{\circ} \mathrm{C}$ ), in defined mineral medium [30] with glucose $\left(20 \mathrm{~g} \mathrm{~L}^{-1}\right)$ and xylose $\left(50 \mathrm{~g} \mathrm{~L}^{-1}\right)$ as carbon sources. One colony was transferred into a $100 \mathrm{~mL}$ shake-flask with $25 \mathrm{~mL}$ medium and incubated $16 \mathrm{~h}$ at $30^{\circ} \mathrm{C}$ with an agitation speed of $160 \mathrm{rpm}$. All $25 \mathrm{~mL}$ were transferred into a $250 \mathrm{~mL}$ shake-flask with $50 \mathrm{~mL}$ defined mineral medium with glucose $\left(5 \mathrm{~g} \mathrm{~L}^{-1}\right)$ and xylose $\left(20 \mathrm{~g} \mathrm{~L}^{-1}\right)$ as carbon sources, and incubated at $30^{\circ} \mathrm{C}$ with an agitation of $160 \mathrm{rpm}$ until exponential growth phase was reached.

\section{Batch cultivations}

Exponential phase shake-flasks cultures were used to inoculate 2 L bioreactors (Sartorius Stedim, BIOSTAT B), with an operative volume of $1.5 \mathrm{~L}$, to a final absorbance of $\mathrm{OD}_{660 \mathrm{~nm}} 0.3$ (CDW about $0.1 \mathrm{~g} \mathrm{~L}^{-1}$ ) in defined mineral medium [30] with glucose $\left(20 \mathrm{~g} \mathrm{~L}^{-1}\right)$ and xylose $\left(20 \mathrm{~g} \mathrm{~L}^{-1}\right)$ as carbon and energy source. Stirrer speed was set at $250 \mathrm{rpm}$ and the initial $\mathrm{pH}$ value at 5 , maintained with $2 \mathrm{M} \mathrm{NaOH}$. The inlet gas flow rate was $0.3 \mathrm{~L} \mathrm{~min}^{-1}$ (0.2 vvm), adjusted with two mass flow controllers (Bronkhornst ${ }^{\oplus}$ High Tech- EL-FLOW ${ }^{\circ}$ Select), one for air and the other for nitrogen $\left(\mathrm{N}_{2}\right)$. The two mass flow controllers were used to set the desired gas mixtures. Batch cultivations were carried out at 30 or $41^{\circ} \mathrm{C}$ and three different concentration of inlet oxygen were tested: $20.95 \%, 11.00 \%$ and $1.75 \%$ of oxygen. Overall, six different fermentation protocols were run in triplicate varying temperature $\left(30\right.$ or $41^{\circ} \mathrm{C}$ ) and inlet oxygen $(20.95 \%$, $11.00 \%$ and $1.75 \%$ of oxygen).

The composition of the fermenter off-gas was on-line measured by a gas analyzer (Omnitec). The gas analyser was always calibrated $24 \mathrm{~h}$ before starting a cultivation using synthetic air containing a defined concentration of $\mathrm{CO}_{2}(1 \%)$.

Samples $(20 \mathrm{~mL})$ were collected regularly from the bioreactor in vials; $1 \mathrm{~mL}$ was used for $\mathrm{OD}_{660 \mathrm{~nm}}$ measurement, after appropriate dilution; $1 \mathrm{~mL}$ was centrifuged at $4^{\circ} \mathrm{C}, 14.000 \mathrm{rpm}$, for $5 \mathrm{~min}$ and supernatants were collected and stored at $-20^{\circ} \mathrm{C}$ for later determination of metabolites concentrations.

The remaining liquid cultures were divided as described later and harvested by centrifugation (2000 rpm $\times 10 \mathrm{~min}$ ).
Pellets were stored at $-80^{\circ} \mathrm{C}$ for subsequent enzymatic and RTq-PCR analysis.

\section{Analytical methods}

Cell growth was spectrophotometrically estimated as $\mathrm{OD}_{660 \mathrm{~nm}}$ (Shimadzu UV-1800) and gravimetrically verified by measuring the cell dry weight (CDW $\mathrm{g} \mathrm{L}^{-1}$ ). For the CBS712 strain we established that a CDW of $1 \mathrm{~g} \mathrm{~L}^{-1}$ correspond to an $\mathrm{OD}_{660 \mathrm{~nm}}$ of 2.86. For dry weight determination, cells were filtered through a dried and preweighed $0.22 \mu \mathrm{m}$-pore membrane (Millipore, USA), washed twice with distilled water and dried in a microwave oven (180 W, $10 \mathrm{~min}$ ). The sample volume filtered was $10 \mathrm{~mL}$ and the dry weight measurements were performed in duplicates for all samples.

Glucose, xylose, xylitol, glycerol, acetate, and ethanol concentrations were HPLC determined using a cationexchange column (Bio-Rad Aminex $\left.{ }^{\oplus} \mathrm{HPX}-87 \mathrm{H}\right)$. The eluent was $5 \mathrm{mM} \mathrm{H}_{2} \mathrm{SO}_{4}$ pumped at $0.6 \mathrm{~mL} \mathrm{~min}^{-1}$ and column temperature was $45^{\circ} \mathrm{C}$. Separated components were detected by a refractive-index detector and peaks were identified by comparing with known standards (SigmaAldrich, St Louis, MO, USA).

\section{Flow cytometric analyses}

Dead or severely compromised cells were detected following Propidium Iodide (PI, Sigma-Aldrich CO., St. Louis, MO, USA) staining. Briefly, cell were washed twice with buffer (TrisHCl $50 \mathrm{mM}, \mathrm{MgCl}_{2} 15 \mathrm{mM}, \mathrm{pH}$ 7.7), resuspended in a PI solution $(0.23 \mathrm{mM})$, incubated in the dark on ice for $20 \mathrm{~min}$ and then analysed by flow-cytometry.

Reactive oxygen species (ROS) were detected by Dihydrorhodamine-123 (DHR-123, Sigma-Aldrich CO., St. Louis, MO, USA) as previously described by [35]. Briefly, cells were incubated for $2 \mathrm{~h}$ with Dihydrorhodamine-123 (5 $\mu \mathrm{g} \mathrm{mL}^{-1}$ from a $2.5-\mathrm{mg} \mathrm{mL}^{-1}$, stock solution in ethanol), washed twice with PBS buffer and then analysed by flow-cytometry.

For both PI and DHR-123 staining positive and negative controls were performed. PI positive control was settled by killing cells with ethanol; ROS positive control was settled by adding to the medium $\mathrm{H}_{2} \mathrm{O}_{2} 6 \mathrm{mM}$. Percentages shown in Figures 3 and 4 have been calculated by taking in account autofluorescence.

Samples were analysed using a Beckman Coulter FC500 flow cytometer (Beckman Coulter, Fullerton, CA, USA) equipped with an Argon ion laser (excitation wavelength $488 \mathrm{~nm}$, laser power $20 \mathrm{~mW}$ ). The fluorescence emissions were measured through a 525-550 nm band pass filter (FL1 parameter) for DHR signals and through a $670 \mathrm{~nm}$ band pass filter (FL4 parameter) for PI signals. The sample flow rate during analysis did not exceeded 500 cells $\mathrm{s}^{-1}$. A total of 25.000 cells were measured for each sample. Data analysis was performed afterwards 
Table 3 Primers list

\begin{tabular}{ccc}
\hline Gene & Orientation & Oligonucleotide sequence \\
\hline XR & Fwd & 5'-CAGAGCCCTTGAGAAGTTGG-3' \\
& Rev & 5'-AAGGATAGTGGGCCGAAACT-3' \\
XDH & Fwd & 5'-GCTGTAGAGCCAGGTGTTCC-3' \\
& Rev & 5'-CAAATCCAGTACCGGCAAGT-3' \\
ATC1 & Fwd & 5'-AGCACCCAGTTITGTTGACC-3' \\
& Rev & 5'-AGGAGAAACCGGCGTAGATT-3' \\
\hline
\end{tabular}

Primers designed and used in the current study.

with Cyflogic software (PerttuTerho, Mika Korkeamäki, CyFlo Ltd).

\section{Protein extraction and enzyme assays}

For total protein extraction, $10 \mathrm{~mL}$ of liquid culture was harvested by centrifugation $(2000 \mathrm{rpm} \times 10 \mathrm{~min})$ and washed twice with $10 \mathrm{~mL}$ of ice-chilled distilled water. Subsequently, cells were resuspended in $1 \mathrm{~mL}$ of distilled water, transferred in FastPrep tube and harvested by centrifugation $(10000 \mathrm{rpm} \times 5 \mathrm{~min})$. Total soluble protein were obtained by three treatments (30 sec, speed 6) of beads beating (Savant Bio 101 FastPrep $^{\circ}$ ), interspersed by $30 \mathrm{sec}$ on ice, in Tris-HCl buffer (0.1 M and pH7.5). After extraction, the debris was pelleted by centrifugation $\left(10000 \mathrm{rpm} \times 5 \mathrm{~min}\right.$ at $\left.4^{\circ} \mathrm{C}\right)$. Supernatants, containing soluble proteins, were transferred to clean tubes and stored at $-20^{\circ} \mathrm{C}$ until required. Protein concentration was measured according to Bradford [51], with bovine serum albumin as the standard.

KmXR activity was spectrophotometrically measured by monitoring the oxidation of $\mathrm{NAD}(\mathrm{P}) \mathrm{H}$ at $340 \mathrm{~nm}$ [52] in a reaction mixture $(1.0 \mathrm{~mL})$ with the following composition: $0.1 \mathrm{M}$ sodium phosphate buffer (pH7), $0.2 \mathrm{M}$ xylose and $0.15 \mathrm{mM} N \mathrm{NAD}(\mathrm{P}) \mathrm{H}$. KmXDH activity was measured by monitoring the reduction of $\mathrm{NAD}^{+}$at $340 \mathrm{~nm}$ [52] in a reaction mixture $(1.0 \mathrm{~mL})$ with the following composition: $0.1 \mathrm{M}$ TrisHCl (pH7), $1 \mathrm{mM} \mathrm{MgCl}_{2}, 50 \mathrm{mM}$ xylitol and $5 \mathrm{mM} \mathrm{NAD}^{+}$. Reactions were started by the addition of substrate. The specific activities of the enzymes were expressed as $\mathrm{U} \mathrm{mg}^{-1}$.

One unit of enzyme activity was defined as the amount of enzyme required to produce $1 \mu \mathrm{mol}$ of $\mathrm{NADH} / \mathrm{NAD}(\mathrm{P})^{+}$ per min under the assay conditions [53].

\section{Total RNA extraction, CDNA synthesis and RTq-PCR}

For total RNA extraction, $5 \mathrm{~mL}$ of liquid culture was harvested by centrifugation $(2000 \mathrm{rpm} \times 10 \mathrm{~min})$ and washed twice with $5 \mathrm{~mL}$ of ice-chilled distilled water. Subsequently, cells were resuspended in $5 \mathrm{~mL}$ of distilled water and the required volume of cells was transferred into a $2 \mathrm{~mL}$ tube. Total RNA was extracted using the Aurum Total RNA Mini Kit (Bio-Rad, USA) according to manufacturer's protocol. The concentration of total
RNA was spectrophotometrically measured (Shimadzu UV-1800; $\left.\mathrm{OD}_{260 \mathrm{~nm}}\right)$ using quartz cuvettes.

About $0.5 \mu \mathrm{g}$ of total RNA was converted into cDNA by reverse transcription in a $20-\mu \mathrm{L}$ reaction mixture using the iScriptcDNASyntesis Kit (Bio-Rad, USA) with the provided random primer mix (5X iScript reaction mix) following the recommended protocol.

The RTq-PCR was performed using the SsoAdvanced SYBR $^{\circ}$ Green Supermix (Bio-Rad, USA) according the manufacturer's instructions. For XR and XDH primer design, sequences deposited as GU574744 and GU574813 were used, respectively. Primer-3 (http://primer3.ut.ee/) was used to design PCR oligonucleotides, listed in Table 3.

The PCR amplification conditions were as follows: initial denaturation for $30 \mathrm{sec}$ at $95^{\circ} \mathrm{C}, \mathrm{PCR}$ amplification for 40 cycles with denaturation for $5 \mathrm{sec}$ at $95^{\circ} \mathrm{C}$, annealing temperature for $10 \mathrm{sec}$ at $58^{\circ} \mathrm{C}$, extension for $5 \mathrm{sec}$ at $65^{\circ} \mathrm{C}$ in a MiniOpticon Real-Time PCR System (BioRad; USA).

The relative expression levels of each targeted gene were normalized by subtracting the corresponding betaactin threshold cycle $\left(C_{T}\right)$ values and the fold increase (or decrease) was calculated through the $2^{-\Delta \Delta C T}$ (Livak) method. Each sample was run in triplicate.

\section{Abbreviations}

KmXR: Kluyveromyces marxianus Xylose Reductase; KmXDH: Kluyveromyces marxianus Xylitol Dehydrogenase; C5 sugar: Sugar with five carbon atoms; RNA: Ribonucleic acid; mRNA: Messenger Ribonucleic acid;

cDNA: Complementary Deoxyribonucleic acid; vvm: Volume of gas per volume of batch per minute; $\mathrm{NAD}^{+}$: Nicotinamide adenine dinucleotide oxidized form; NADH: Nicotinamide adenine dinucleotide reduced form; $\mathrm{NADP}^{+}$: Nicotinamide adenine dinucleotide phosphate oxidized form; NADPH: Nicotinamide adenine dinucleotide phosphate reduced form; ROS: Reactive oxygen species; $\mathrm{C}_{\mathrm{t}}$ : Threshold cycle; $\mathrm{H}_{2} \mathrm{O}_{2}$ : Hydrogen peroxide; YPX: Medium containing Yeast extract, Peptone and Xylose; rpm: Revolutions per minute; PCR: Polymerase chain reaction; RTq-PCR: Quantitative reverse transcriptase polymerase chain reaction; CDW: Cell dry weight; OD: Optical density; HPLC: High pressure liquid chromatography; PI: Propidium iodide; DHR-123: Dihydrorhodamine 123; $\mathrm{H}_{2} \mathrm{SO}_{4}$ : Sulphuric acid; $\mathrm{N}_{2}$ : Nitrogen; $\mathrm{NaOH}$ : Sodium hydroxide; $\mathrm{MgCl}_{2}$ : Magnesium chloride solution; Tris $\mathrm{HCl}$ : Tris hydrochloride buffer; FL1: Filter $n^{\circ} 1$; FL4: Filter $n^{\circ} 4$; PBS: Phosphate-buffered saline.

\section{Competing interests}

The authors declare that they have no competing interests.

\section{Authors' contributions}

LS carried out the fermentation experiments, the flow cytometric assays, the enzymatic and the transcriptional assays, participated in the evaluation of the data and in compiling the manuscript. SP carried out the fermentation and the flow cytometric assays, participated in the evaluation of the data. LR contributed to the data interpretation and manuscript revision. DP and PB conceived the study, participated in its design, data interpretation and compiled the manuscript. All the authors have read and approved the final manuscript.

\section{Acknowledgements}

The research leading to these results has received funding from the European Community's Seventh Framework Programme (FP7/2007-2013) under the project NEMO (Grant agreement no. 222699). The authors gratefully acknowledge Gabriele Erba for technical contribution. 


\section{Author details}

${ }^{1}$ University of Milano Bicocca, Piazza della Scienza 2, 20126 Milan, Italy. ${ }^{2}$ VTT Technical Research Centre of Finland, Espoo FI-02044 VTT, Finland. ${ }^{3}$ Current address: Sacco srl, Via Manzoni, 29/A, 22071 Cadorago Co, Italy.

Received: 10 January 2014 Accepted: 4 April 2014

Published: 8 April 2014

\section{References}

1. Porro D, Branduardi P: Yeast cell factory: fishing for the best one or engineering it? Microb Cell Factories 2009, 8:51.

2. Lane MM, Morrissey JP: Kluyveromyces marxianus: A yeast emerging from its sister's shadow. Fungal Biol Rev 2010, 24:7-26.

3. Lane MM, Burke N, Karreman R, Wolfe KH, O'Byrne CP, Morrissey JP: Physiological and metabolic diversity in the yeast Kluyveromyces marxianus. Antonie Van Leeuwenhoek / 2011, 100:507-519.

4. Belloch C, Querol A, Garcia MD, Barrio E: Phylogeny of the genus Kluyveromyces inferred from the mitochondrial cytochrome-c oxidase II gene. Int J Syst Evol Microbiol 2000, 50:405-416.

5. Gonzalez-Siso MI, Freire-Picos MA, Ramil E, Gonzalez-Dominguez M, Torres AR, Cerdan ME: Respirofermentative metabolism in Kluyveromyces lactis: insights and perspectives. Enzyme Microb Technol 2000, 26:699-705.

6. Schaffrath R, Breunig KD: Genetics and molecular physiology of the yeast Kluyveromyces lactis. Fungal Genet Biol 2000, 30:173-190.

7. van Ooyen AJJ, Dekker P, Huang M, Olsthoorn MMA, Jacobs DI, Colussi PA, Taron $\mathrm{CH}$ : Heterologous protein production in the yeast Kluyveromyces lactis. FEMS Yeast Res 2006, 6:381-392.

8. Lee YJ, Kim CS, Oh DK: Lactulose production by beta-galactosidase in permeabilized cells of Kluyveromyces lactis. Appl Microbiol Biotechnol 2004, 64:787-793

9. Bianchi MM, Brambilla L, Protani F, Liu CL, Lievense J, Porro D: Efficient homolactic fermentation by Kluyveromyces lactis strains defective in pyruvate utilization and transformed with the heterologous $L D H$ gene. Appl Environ Microbiol 2001, 67:5621-5625

10. Breuning KD, Steensma HY: Kluyveromyces lactis: genetics, physiology and application. Funct Genet Ind Yeasts Top Curr Genet 2003, 2:171-205.

11. Fonseca GG, Gombert AK, Heinzle E, Wittmann C: Physiology of the yeast Kluyveromyces marxianus during batch and chemostat cultures with glucose as the sole carbon source. FEMS Yeast Res 2007, 7:422-435.

12. Groeneveld P, Stouthamer AH, Westerhoff HV: Super life - how and why 'cell selection' leads to the fastest-growing eukaryote. FEBS J 2009, 276:254-270.

13. Anderson PJ, McNeil K, Watson K: High-efficiency carbohydrate fermentation to ethanol at temperatures above $40^{\circ} \mathrm{C}$ by Kluyveromyces marxianus var marxianus isolated from sugar mills. Appl Environ Microbiol 1986, 51:1314-1320.

14. Rouwenhorst RJ, Visser LE, Vanderbaan AA, Scheffers WA, Vandijken JP: Production, distribution, and kinetic properties of inulinase in continuous cultures of Kluyveromyces marxianus CBS 6556. Appl Environ Microbiol 1988, 54:1131-1137.

15. Steensma HY, Dejongh FCM, Linnekamp M: The use of electrophoretic karyotypes in the classification of yeasts: Kluyveromyces marxianus and Kluyveromyces lactis. Curr Genet 1988, 14:311-317.

16. Banat IM, Nigam $P$, Marchant R: Isolation of thermotolerant, fermentative yeasts growing at $52^{\circ} \mathrm{C}$ and producing ethanol at $45^{\circ} \mathrm{C}$ and $50^{\circ} \mathrm{C}$. World J Microbiol Biotechnol 1992, 8:259-263.

17. Rodrussamee N, Lertwattanasakul N, Hirata K, Suprayogi Limtong S, Kosaka T, Yamada M: Growth and ethanol fermentation ability on hexose and pentose sugars and glucose effect under various conditions in thermotolerant yeast Kluyveromyces marxianus. Appl Microbiol Biotechnol 2011, 90:1573-1586.

18. Ballesteros M, Oliva JM, Negro MJ, Manzanares P, Ballesteros I: Ethanol from lignocellulosic materials by a simultaneous saccharification and fermentation process (SFS) with Kluyveromyces marxianus CECT 10875. Process Biochem 2004, 39:1843-1848

19. Castro RC, Roberto IC: Selection of a thermotolerant Kluyveromyces marxianus strain with potential application for cellulosic ethanol production by Simultaneous Saccharification and Fermentation. Appl Biochem Biotechnol 2013, 3:1553-1564.

20. Goshima T, Tsuji M, Inoue H, Yano S, Hoshino T, Matsushika A: Bioethanol production from lignocellulosic biomass by a novel Kluyveromyces marxianus strain. Biosci Biotechnol Biochem 2013, 77:1505-1510.
21. Matsushika A, Inoue H, Kodaki T, Sawayama S: Ethanol production from xylose in engineered Saccharomyces cerevisiae strains: current state and perspectives. Appl Microbiol Biotechnol 2009, 84:37-53.

22. Lin $Y$, Tanaka S: Ethanol fermentation from biomass resources: current state and prospects. Appl Microbiol Biotechnol 2006, 69:627-642.

23. Limtong S, Sringiew C, Yongmanitchai W: Production of fuel ethanol at high temperature from sugar cane juice by a newly isolated Kluyveromyces marxianus. Bioresour Technol 2007, 98:3367-3374.

24. Suutari M, Liukkonen $\mathrm{K}$, Laakso S: Temperature adaptation in yeasts: the role of fatty acids. J Gen Microbio/ 1990, 136:1469-1474.

25. Zhang B, Zhang L, Wang D, Gao X, Hong J: Identification of a xylose reductase gene in the xylose metabolic pathway of Kluyveromyces marxianus NBRC1777. J Ind Microbiol Biotechnol 2011, 38:2001-2010.

26. Fonseca GG, Heinzle E, Wittmann C, Gombert AK: The yeast Kluyveromyces marxianus and its biotechnological potential. Appl Microbiol Biotechnol 2008, 79:339-354.

27. Rocha SN, Abrahao-Neto J, Gombert AK: Physiological diversity within the Kluyveromyces marxianus species. Antonie Van Leeuwenhoek 2011, 100:619-630.

28. Llorente B, Malpertuy A, Blandin G, Artiguenave F, Wincker P, Dujon B: Genomic exploration of the hemiascomycetous yeasts: 12. Kluyveromyces marxianus var. marxianus. FEBS Lett 2000, 487:71-75.

29. Lulu L, Zhang L, Wang D, Gao X, Tamaki H, Kumagai H, Hong J: Identification of a xylitol dehydrogenase gene from Kluyveromyces marxianus NBRC1777. Mol Biotechnol 2013, 53:159-169.

30. Verduyn C, Postma E, Scheffers WA, Vandijken JP: Effect of benzoic-acid on metabolic fluxes in yeasts: a continuous-culture study on the regulation of respiration and alcoholic fermentation. Yeast 1992, 8:501-517.

31. Sansonetti S, Hobley TJ, Curcio S, Villadsen J, Sin G: Use of continuous lactose fermentation for ethanol production by Kluveromyces marxianus for verification and extension of a biochemically structured model. Bioresour Technol 2013, 130:703-709.

32. Vandijken JP, Scheffers WA: Redox balances in the metabolism of sugars by yeasts. FEMS Microbiol Rev 1986, 32:199-224.

33. Winkelhausen E, Kuzmanova S: Microbial conversion of D-xylose to xylitol. J Ferment Bioeng 1998, 86:1-14

34. Sasaki DT, Dumas SE, Engleman EG: Discrimination of viable and non viable cells using propidium iodide in 2 color immunofluorescence. Cytometry 1987, 8:413-420.

35. Madeo F, Frohlich E, Ligr M, Grey M, Sigrist SJ, Wolf DH, Frohlich KU: Oxygen stress: A regulator of apoptosis in yeast. J Cell Biol 1999 145:757-767.

36. Kotter P, Ciriacy M: Xylose fermentation by Saccharomyces cerevisiae. Appl Microbiol Biotechnol 1993, 38:776-783.

37. Bruinenberg PM, Debot PHM, Vandijken JP, Scheffers WA: The role of redox balances in the anaerobic fermentation of xylose by yeasts. Appl Microbiol Biotechnol 1983, 18:287-292

38. Jeong H, Lee D-H, Kim SH, Kim H-J, Lee K, Song JY, Kim BK, Sung BH, Park JC, Sohn JH, Koo HM, Kim JF: Genome sequence of the thermotolerant yeast Kluyveromyces marxianus var. marxianus KCTC 17555. Eukaryot Cell 2012, 11:1584-1585.

39. Blank LM, Lehmbeck F, Sauer U: Metabolic-flux and network analysis in fourteen hemiascomycetous yeasts. FEMS Yeast Res 2005, 5:545-558.

40. Salusjarvi L, Kankainen M, Soliymani R, Pitkanen JP, Penttila M, Ruohonen L: Regulation of xylose metabolism in recombinant Saccharomyces cerevisiae. Microb Cell Factories 2008, 7:18.

41. Yablochkova EN, Bolotnikova OI, Mikhailova NP, Nemova NN, Ginak Al: The activity of xylose reductase and xylitol dehydrogenase in yeasts. Microbiology 2003, 72:414-417.

42. Isabel Gonzalez Siso M, Garcia Leiro A, Tarrio N, Esperanza Cerdan M: Sugar metabolism, redox balance and oxidative stress response in the respiratory yeast Kluyveromyces lactis. Microb Cell Factories 2009, 8:46.

43. Saliola M, Tramonti A, Lanini C, Cialfi S, De Biase D, Falcone C: Intracellular NADPH Levels Affect the Oligomeric State of the Glucose 6-Phosphate Dehydrogenase. Eukaryot Cell 2012, 11:1503-1511.

44. Zhang B, Li L, Zhang J, Gao X, Wang D, Hong J: Improving ethanol and xylitol fermentation at elevated temperature through substitution of xylose reductase in Kluyveromyces marxianus. J Ind Microbiol Biotechnol 2013, 40:305-316.

45. Wang R, Li L, Zhang B, Gao X, Wang D, Hong J: Improved xylose fermentation of Kluyveromyces marxianus at elevated temperature 
through construction of a xylose isomerase pathway. J Ind Microbiol Biotechnol 2013, 40:841-854.

46. Dos Santos VC, Soares Braganca CR, Vieira Passos FJ, Lopes Passos FM: Kinetics of growth and ethanol formation from a mix of glucose/xylose substrate by Kluyveromyces marxianus UFV-3. Antonie Van Leeuwenhoek 1 2013, 103:153-161.

47. Oliva JM, Saez F, Ballesteros I, Gonzalez A, Negro MJ, Manzanares P, Ballesteros M: Effect of lignocellulosic degradation compounds from steam explosion pretreatment on ethanol fermentation by thermotolerant yeast Kluyveromyces marxianus. Appl Biochem Biotechnol 2003, 105:141-153.

48. Moreno AD, Ibarra D, Ballesteros I, Gonzalez A, Ballesteros M: Comparing cell viability and ethanol fermentation of the thermotolerant yeast Kluyveromyces marxianus and Saccharomyces cerevisiae on steam-exploded biomass treated with laccase. Bioresour Technol 2013, 135:239-245.

49. Lee JS, Huh WK, Lee BH, Baek YU, Hwang CS, Kim ST, Kim YR, Kang SO: Mitochondrial $\mathrm{NADH}$-cytochrome $b(5)$ reductase plays a crucial role in the reduction of D-erythroascorbyl free radical in Saccharomyces cerevisiae. Biochim Biophys Acta 2001, 1527:31-38.

50. Branduardi P, Fossati T, Sauer M, Pagani R, Mattanovich D, Porro D: Biosynthesis of Vitamin $C$ by yeast leads to increased stress resistance. Plos One 2007, 2:e1092.

51. Bradford MM: Rapid and sensitive method for quantitation of microgram quantities of protein utilizing principle of protein-dye binding. Anal Biochem 1976, 72:248-254.

52. Smiley KL, Bolen PL: Demostration of D-xylose reductase and D-xylito dehydrogenase in Pachysolen tannophilus. Biotechnol Lett 1982, 4:607-610.

53. Tiwari MK, Moon H-J, Jeya M, Lee J-K: Cloning and characterization of a thermostable xylitol dehydrogenase from Rhizobium etli CFN42. Appl Microbiol Biotechnol 2010, 87:571-581.

doi:10.1186/1475-2859-13-5

Cite this article as: Signori et al:: Effect of oxygenation and temperature on glucose-xylose fermentation in Kluyveromyces marxianus CBS712 strain. Microbial Cell Factories 2014 13:51.

\section{Submit your next manuscript to BioMed Central and take full advantage of:}

- Convenient online submission

- Thorough peer review

- No space constraints or color figure charges

- Immediate publication on acceptance

- Inclusion in PubMed, CAS, Scopus and Google Scholar

- Research which is freely available for redistribution 